University of Wollongong

Research Online

Faculty of Engineering - Papers (Archive)

Faculty of Engineering and Information

Sciences

9-3-2008

\title{
Vacuum Preloading Techniques - Recent Developments and Applications
}

J. Chu

Nanyang Technological University, Singapore

S. Yan

Tianjin University, China

Buddhima Indraratna

University of Wollongong, indra@uow.edu.au

Follow this and additional works at: https://ro.uow.edu.au/engpapers

Part of the Engineering Commons

https://ro.uow.edu.au/engpapers/420

\section{Recommended Citation}

Chu, J.; Yan, S.; and Indraratna, Buddhima: Vacuum Preloading Techniques - Recent Developments and Applications 2008.

https://ro.uow.edu.au/engpapers/420

Research Online is the open access institutional repository for the University of Wollongong. For further information contact the UOW Library: research-pubs@uow.edu.au 


\title{
Vacuum Preloading Techniques - Recent Developments and Applications
}

\author{
Jian Chu ${ }^{1}$, Shuwang Yan $^{2}$, and Buddhima Indraranata ${ }^{3}$, F. ASCE \\ ${ }^{1}$ School of Civil and Environmental Engineering, Nanyang Technological University, Blk N1, 50 \\ Nanyang Ave, Singapore 639798, Singapore cjchu@ntu.edu.sg. \\ 2 Geotechnical Research Centre, Tianjin University, Tianjin, China, shuwangyang@ @ tju.edu.cn . \\ ${ }^{3}$ School of Civil, Mining and Environmental Engineering, Faculty of Engineering, University of \\ Wollongong, Wollongong City, NSW 2522, Australia, indra@uw.edu.au.
}

ABSTRACT: In this paper, an overview on the mechanisms, techniques and applications of the vacuum preloading method are presented. Some recent developments in the vacuum preloading techniques, including the use of new materials, the expansion of the method, and new analysis or numerical modeling methods are briefly summarized.

\section{INTRODUCTION}

It has been 56 years since the idea of vacuum preloading was proposed by Kjellman (1952). Since then, the vacuum preloading method has evolved into a mature and efficient technique for the treatment of soft clay. This method has been successfully used for soil improvement or land reclamation projects in a number of countries (Holtz 1975; Chen and Bao 1983; Bergado et al. 1998; Chu et al. 2000; Indraratna et al. 2005). With the merging of new materials and new technologies, this method has been further improved in recent years. A brief overview of this technique and the recent developments and applications is given in this paper. In adopting this technique, sand drains and recently prefabricated vertical drains (PVDs) have often been used to distribute the vacuum pressure and discharge pore water. A nominal vacuum load of $80 \mathrm{kPa}$ is normally used in design although a higher vacuum pressure of up to $90 \mathrm{kPa}$ may be achieved sometimes. When a surcharge load higher than $80 \mathrm{kPa}$ is required, a combined vacuum and fill surcharge can be applied. For the treatment of very soft ground, the vacuum preloading method is faster than the fill surcharge method, as the $80 \mathrm{kPa}$ vacuum pressure can be applied almost instantly, without causing stability problem. The vacuum preloading method is also cheaper when compared with the fill surcharge method for an equivalent load (Chu et al. 2000). The vacuum preloading method has also been incorporated in the land reclamation process when clay slurry dredged from seabed is used as fill material for land reclamation. As the clay slurry fill is too soft for fill surcharge to be applied, the vacuum preloading method is ideally used for the consolidation of the clay slurry. Thousands of hectares of land have been 
reclaimed in Tianjin, China, using this method (Chen and Bao 1983; Yan and Chu 2005). In recent years, a similar vacuum technique has also been used for site remediation works (Lindhult et al. 1995). A variation of this technique has also been adopted for the stabilization of retaining structures (Miyazaki et al. 2005). The mechanisms of vacuum preloading and conventional and innovative techniques related to equipment, materials, monitoring, analysis and numerical simulations are discussed in the followings. A case history is also presented to illustrate the application of the combined vacuum and fill surcharge preloading method.

\section{MECHANISMS}

The principles and mechanism of vacuum preloading have been well explained in the literature, e.g., Kjellman (1952), Holtz (1975), Chen and Bao (1983), Chu et al. (2000), and Indraratna et al. (2004). As a comparison with the fill surcharge preloading, the pore water pressure and effective stress change processes in vacuum preloading can be further examined as follows.

The consolidation process of soil under surcharge load has been well understood and can be illustrated using the spring analogy as shown in Fig. 1(a). For the convenience of explanation, the pressures in Fig. 1 are given in absolute values and $p_{a}$ is the atmospheric pressure. As shown in Fig. 1a, the instance when a surcharge load, $\Delta \mathrm{p}$, is applied, it is the excess pore water pressure that takes the load. Therefore, for saturated soil, the initial excess pore water pressure, $\Delta \mathrm{u}_{0}$, is the same as the surcharge $\Delta \mathrm{p}$. Gradually, the excess pore water pressure dissipates and the load is transferred from water to the spring (i.e., the soil skeleton) in the model shown in Fig. 1(a). The amount of effective stress increment equals to the amount of pore water pressure dissipation, $\Delta \mathrm{p}-\Delta \mathrm{u}$ (Fig. 1(a)). At the end of consolidation, $\Delta \mathrm{u}=0$ and the total gain in the effective stress is the same as the surcharge, $\Delta \mathrm{p}$ (Fig. 1(a)). It should be noted that the above process is not affected by the atmospheric pressure, $\mathrm{p}_{\mathrm{a}}$.

The mechanism of vacuum preloading can also be illustrated in the same way using the spring analogy as shown in Fig. 1(b). When a vacuum load is applied to the system shown in Fig. 1(b), the pore water pressure in the soil reduces. As the total stress applied does not change, the effective stress in the soil increases. The instance when the vacuum load, $-\Delta \mathrm{u}$, is applied, the pore water pressure in the soil is still $\mathrm{p}_{\mathrm{a}}$. Gradually the pore pressure is reducing and the spring starts to be compressed, that is, the soil skeleton starts to gain effective stress. The amount of the effective stress increment equals to the amount of pore water pressure reduction, $\Delta \mathrm{u}$, which will not exceed the atmospheric pressure, $\mathrm{p}_{\mathrm{a}}$, or normally $80 \mathrm{kPa}$ in practice.

\section{TECHNIQUES}

A typical vacuum preloading system is shown in Fig. 2 (Chu et al. 2000). PVDs and the horizontal pipes are used for the distribution of vacuum pressure and the dissipation of pore water. The horizontal pipes and the top ends of the PVDs are buried in a sand blanket made of course sand which transmits the vacuum to the PVDs. Corrugated flexible pipes (50 to $100 \mathrm{~mm}$ in diameter) are normally used as horizontal pipes. These pipes are perforated and wrapped with a permeable fabric 
textile to act as a filter layer as shown in Fig. 3(a). The horizontal pipes are connected to the main vacuum distribution pipes. Three layers of thin PVC membranes are often used to seal the area to be improved by vacuum preloading. The membranes are buried into a trench at the four boundaries of the area. For this reason, the entire soil improvement area often needs to be subdivided into small areas to facilitate the installation of the membranes. Vacuum pressure was applied using vacuum pumps continuously for the whole duration of preloading.

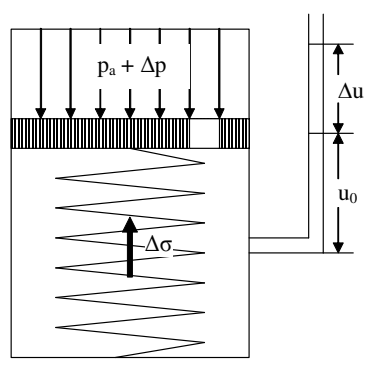

$u_{0}=p_{a}$

$\Delta \sigma=p_{a}+\Delta p-\left(u_{0}+\Delta u\right)=\Delta p-\Delta u$

(a)
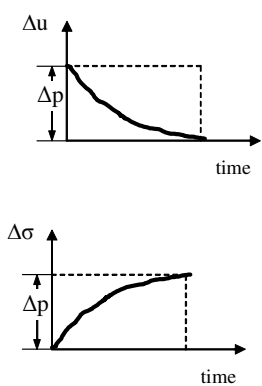
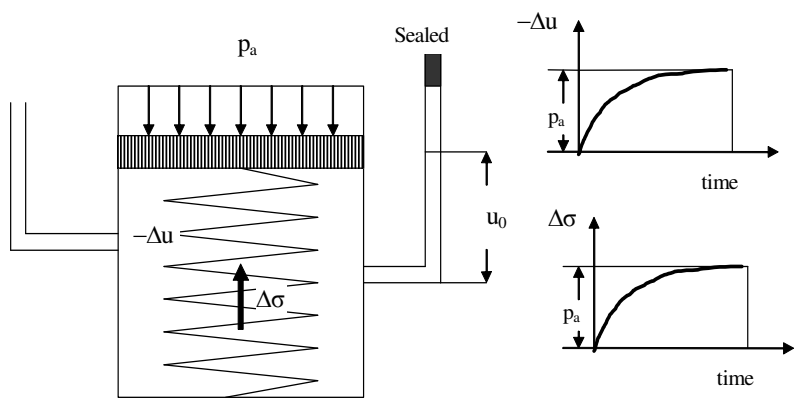

$$
\begin{aligned}
& u_{0}=p_{a} \\
& \Delta \sigma=p_{a}-\left(u_{0}-\Delta u\right)=\Delta u
\end{aligned}
$$

(b)

FIG 1. Spring analog of consolidation process (a) under fill surcharge; (b) under vacuum load

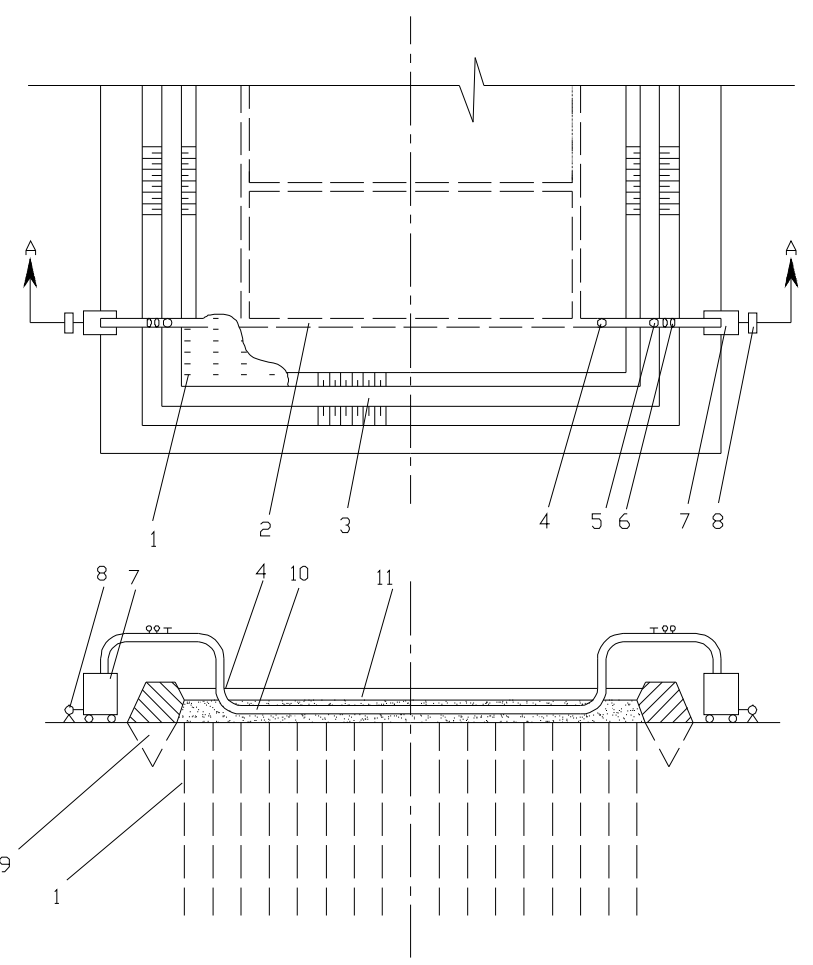

1, PVDs; 2, horizontal pipes; 3, revetment; 4, water outlet; 5 , valve; 6 , vacuum gauge; 7, jet pump; 8 , centrifugal pump; 9, trench; 10, main vacuum pipes; 11 , sealing membrane.

FIG 2 A Schematic illustration of the vacuum preloading system 


\section{NEW DEVELOPMENTS}

\section{Use of Drain Panels}

Several improvements to the vacuum preloading technique presented in Fig. 2 have been made in the recent years. The first is the use of drain panels as shown in Fig. 3(b), instead of the pipes. This is to ensure the drainage channels will still function well under a high surcharge pressure, as in the case of combined fill and vacuum preloading. The drainage panels also provide better channels for distributing vacuum pressure and water discharging. Some drainage panels also have slots for direction connection with PVDs and thus improve the efficiency of the system.

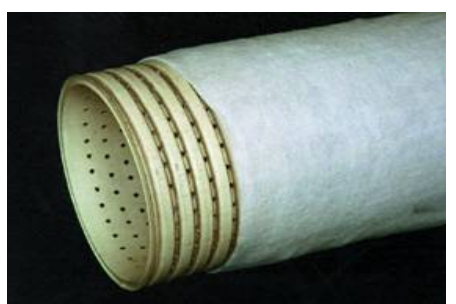

(a) Corrugated flexible pipes

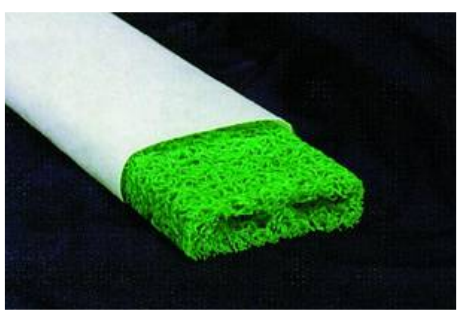

(b) Other types of geo-composites

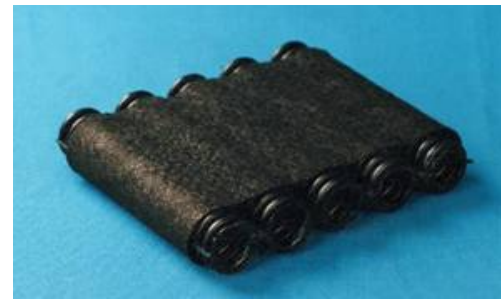

FIG 3 Horizontal pipes used for vacuum preloading

\section{Membrane Free Techniques}

When the total area has to be subdivided into a number of sections to facilitate the installation of membrane, the vacuum preloading can only be carried out one section after another. This may not be efficient when the vacuum preloading method is used for land reclamation over a large area. One way to overcome this problem is to

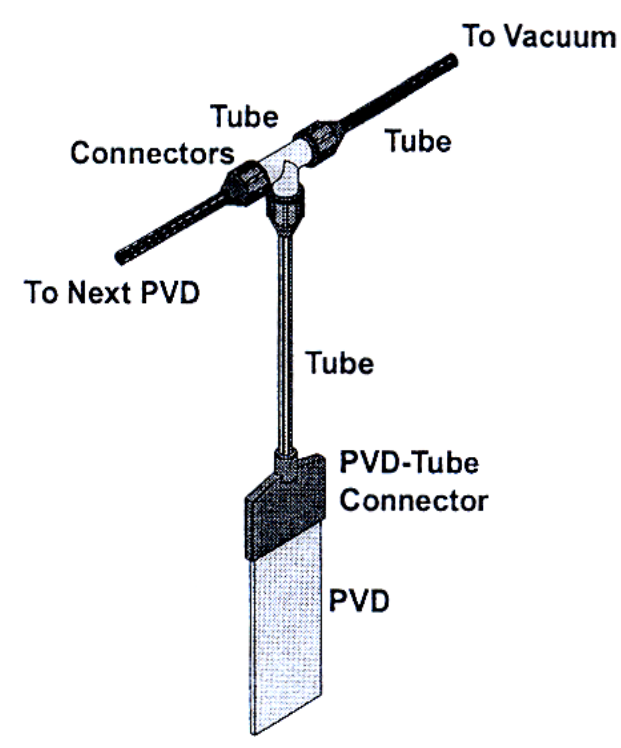

FIG. 4 PVD and tubing for vacuum preloading (after Seah, 2006) connect the vacuum channel directly to each individual drain using a tubing system as shown in Fig. 4. In this way, the channel from the top of the PVD to the vacuum line is sealed. Hence a sand blanket and membranes are not required. This system has been used for the construction of the new Bangkok International Airport (Seah, 2006). However, as such a system does not provide an airtight condition for the entire area, the efficiency of the system can be low. The vacuum pressure applied may only be $50 \mathrm{kPa}$ or lower (Seah, 2006). This method also only works when the soil layer to be improved is dominantly clay with low permeability.

Another method to do sway with the membrane is to use the so-called low level vacuum preloading method (Yan and Cao, 2006). This method is schematically illustrated in Fig. 5. When clay slurry is used as fill for land reclamation, the vacuum pipes can be 
installed at the seabed or a level a few meters below the ground surface. In this way, clay slurry fill can be placed on top of the vacuum pipes. As clay has a low permeability, the fill material will provide a good sealing cap and membranes will be not required. However, this method is not free of problems. Tension cracks will develop in the top layer when dried under the sunlight. The vacuum pressure may not be distributed properly unless a drainage blanket is used at the level where the drainage pipes are installed or the individual drains are connected to the vacuum pipes directly. It is also difficult to install drainage pipes or panels underwater. Nevertheless, this method does not require the construction of inner dikes for subdivision and thus cuts down the project costs substantially.

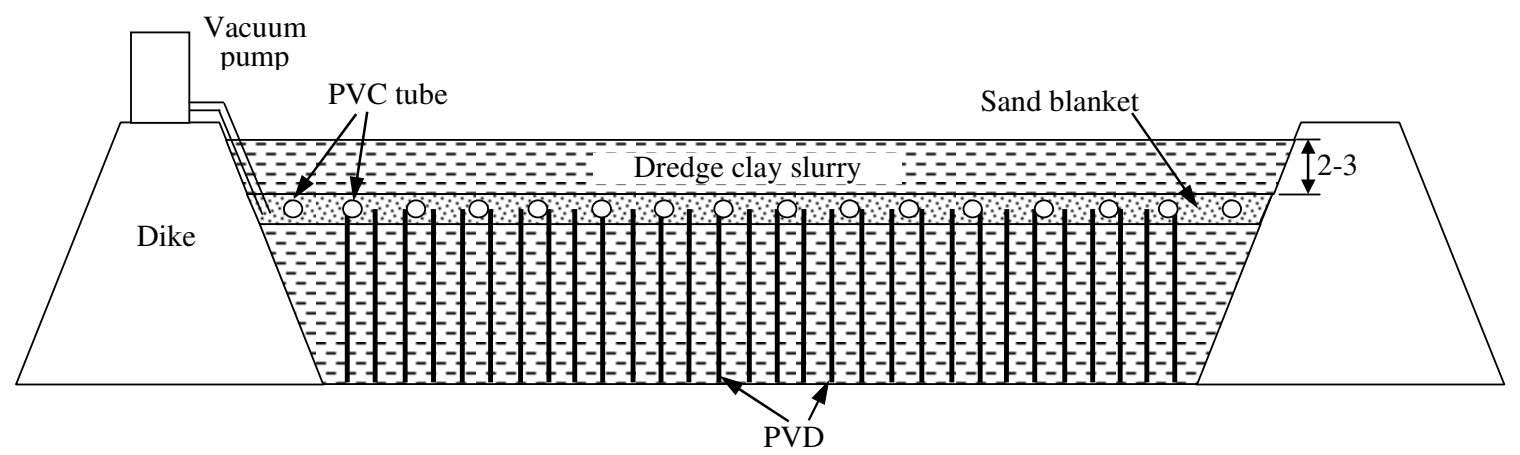

FIG. 5 No membrane vacuum preloading method

\section{Dealing with Inter-bedded Permeable Layers}

The vacuum preloading method may not work well when the subsoil is inter-bedded with sand lenses or permeable layers that extend beyond the boundary of the area to be improved, such as the improvement of soft soil below sand fill for reclaimed land. In this case, a cut-off wall is required to be installed around the boundary of entire area to be treated. One example is given by Tang and Shang (2000), in which a $120 \mathrm{~cm}$ wide and $4.5 \mathrm{~m}$ deep clay slurry wall was used as a cut-off wall in order to improve the soft clay below a silty sand layer. However, installation of cut-off walls is expensive when the total area to be treated is large. An alternative method is to use PVD with impermeable plastic sleeve for the section of the PVD that passes through the permeable layer. However, this is workable only when we know fairly accurately the thickness of the permeable layer, which is often the case for reclaimed land.

\section{Drainage Enhanced Dynamic Compaction Method}

One shortcoming of the vacuum preloading or the surcharge preloading method in general is that it is time consuming. One way to overcome this problem is to combine vacuum preloading with dynamic compaction. The basic idea is to use dynamic compaction with low impact energy to generate excess pore pressure which can be then dissipated quickly under the vacuum action (Chu et al. 2005). The quick dissipation of pore pressure in turn improves the efficiency of dynamic compaction. This method has been used successfully in a number of projects in China (Xu et al. 2003). 


\section{FIELD MONITORING AND DATA INTERPRETATION}

Field monitoring is essential for projects using vacuum preloading as it is the only way to assess the effect of soil improvement using vacuum preloading. Normally, settlements of different soil layers, pore water pressure and lateral displacement at different elevations are measured. The average degree of consolidation (DOC) can be evaluated based on either the settlement or pore pressure data. The DOC estimated using settlement is affected by the methods used for predicting the ultimate settlement.

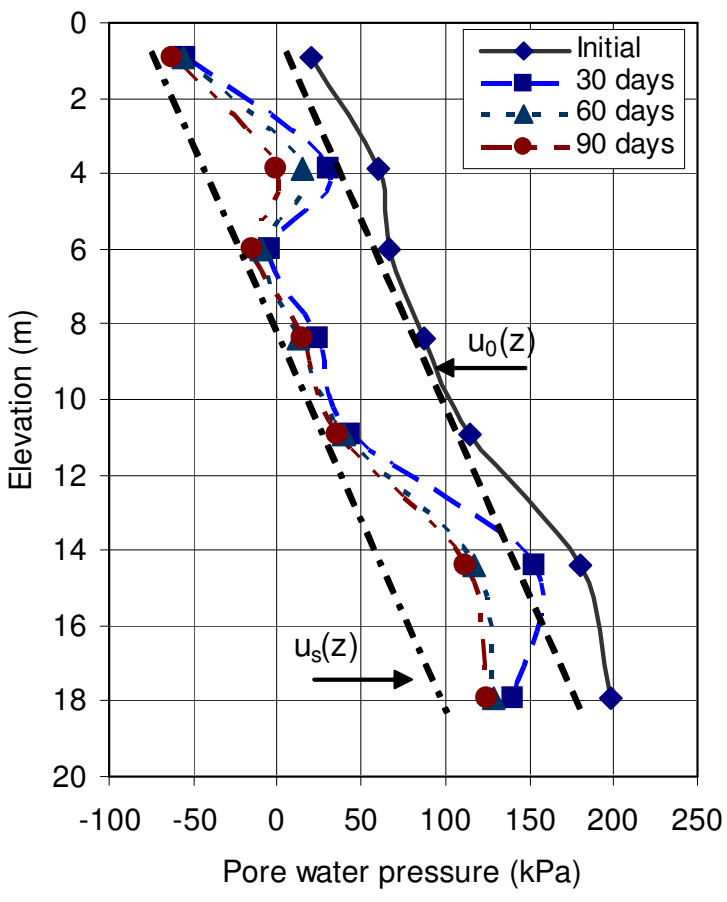

FIG. 6 Pore pressure profiles used for the calculation of DOC.

Using the monitored pore water pressure data, the pore water pressure distribution versus depth profiles can be plotted for the initial, final, and any intermediate states. The DOC can be estimated based on the pore water pressure profile using the method suggested by Chu and Yan (2005). One example is shown in Fig. 6. As shown by Chu and Yan (2005) using case studies, the DOC estimated using settlement data is generally greater than that using pore water pressure data. This can be partially explained by the fact that when only limited instruments can be used, settlement and pore water pressure gauges will be installed only at the locations where the maximum settlement and pore water pressure will be likely to occur. As a result, the DOC tends to be overestimated when settlement data are used and underestimated when pore water pressure data are used. It has bee suggested by Chu and Yan (2005) that for contracting purpose, it is necessary to specify the method used to calculate the DOC and indicate clearly whether the DOC is to be estimated using settlement or pore water pressure data.

\section{NUMERICAL MODELLING}

A case study of a combined vacuum and surcharge load through prefabricated vertical drains (PVD) at a storage yard at Tianjin Port, China was investigated using a finite element analysis (Rujikiatkamjorn et al. 20007). At this site, a combination of $80 \mathrm{kPa}$ vacuum pressure and $40 \mathrm{kPa}$ of fill surcharge was required to improve the soft soil condition and avoid any instability problems. Figure 6 presents soil profile with its relevant soil properties. The vertical cross section and the locations of field instrumentation are shown in Fig. 7a. This included settlement gauges, pore water pressure transducers, multi-level gauges, inclinometers and piezometers. PVDs of $20 \mathrm{~m}$ in length (Section: $100 \mathrm{~mm} \times 3 \mathrm{~mm}$ ) were installed in a square pattern @ 1m spacing. 
The finite element mesh contained elements having 8-node bi-quadratic displacement and bilinear pore pressure shape functions (Fig. 7b).

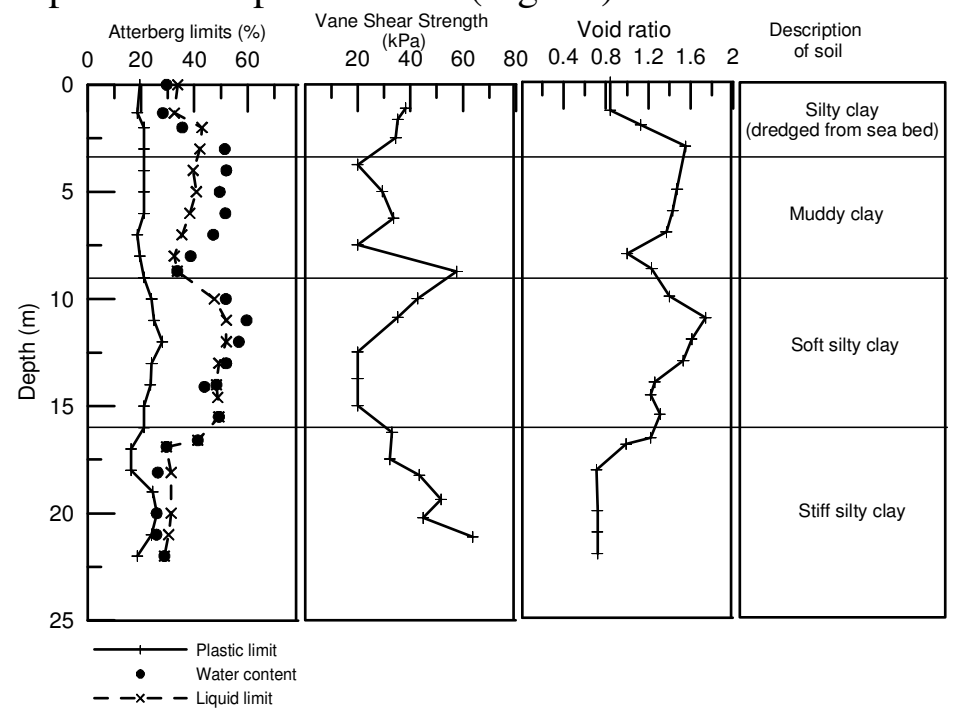

FIG. 6 General soil profile and properties at Tianjin port (adopted from Rujikiatkamjorn et al. 2007)

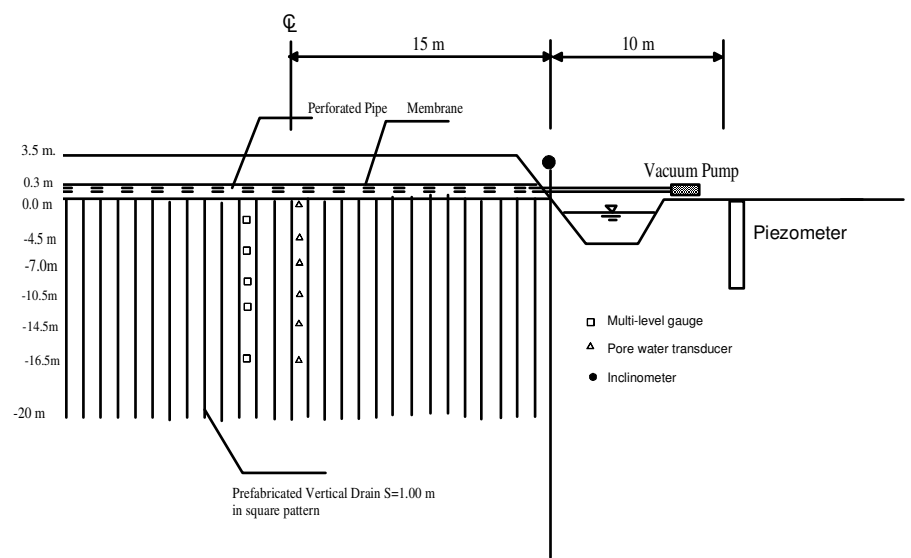

(a)

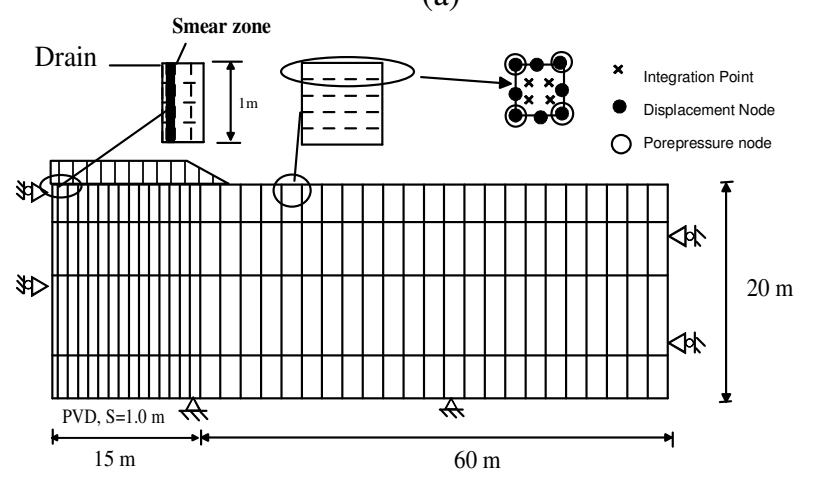

(b)

FIG. 7 (a) Vertical cross section A-A and locations of monitoring instruments and

(b) Finite element mesh for plane strain analysis (adopted from Rujikiatkamjorn et al. 2007) 
Figures 8 and 9 show a comparison between the predicted and recorded field settlements and excess pore pressure, respectively. The predicted consolidation settlement and excess pore pressure are in accordance with the measured results. The mean excess pore pressure is negative (suction), avoiding any potential undrained failures (Indraratna et al., 2005). Figure 10 illustrates the comparison between the measured and predicted lateral movements at the toe of embankment after 180 days. The negative lateral displacement denotes an inward soil movement towards the centerline of the embankment. The predictions at shallow depth (i.e., 0-5m) agree well with the field data, but they slightly underestimate the field results at $5-10 \mathrm{~m}$ depth (middle of the soft clay layer). It can be seen that vacuum consolidation can minimise any lateral outward yield of soil to increase stability of soft clay foundations.

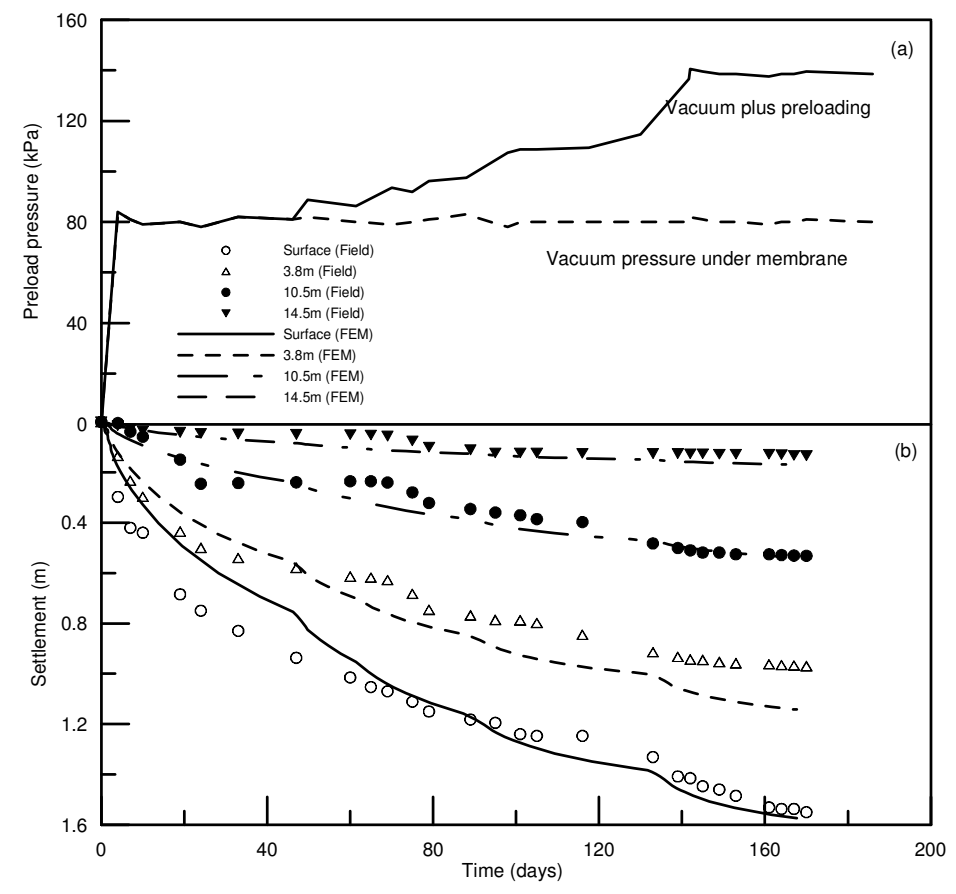

FIG. 8 Section II: (a) Loading history and (b) Consolidation settlements (adopted from Rujikiatkamjorn et al. 2007)

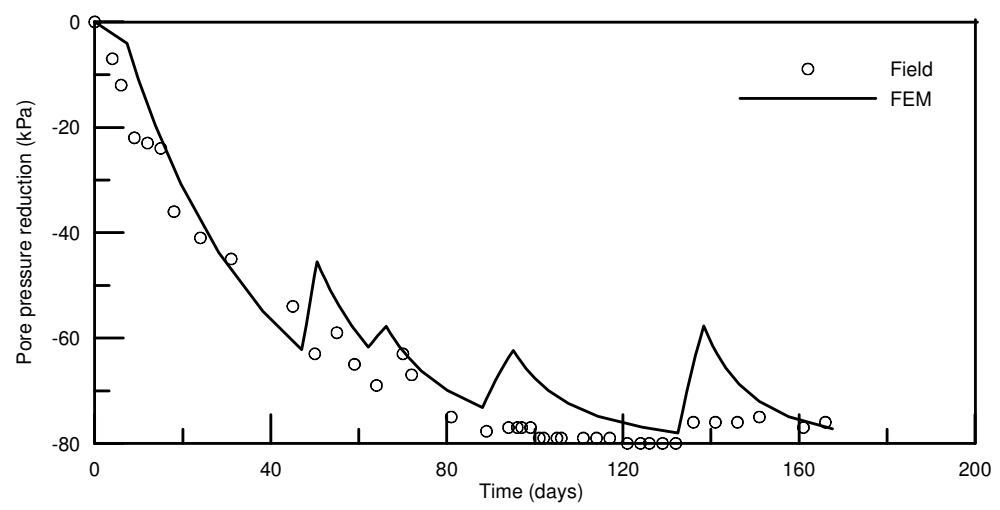

FIG. 9 Excess pore pressure predictions at $0.25 \mathrm{~m}$ away from the embankment and at 5.5m depth (adopted from Rujikiatkamjorn et al. 2007) 


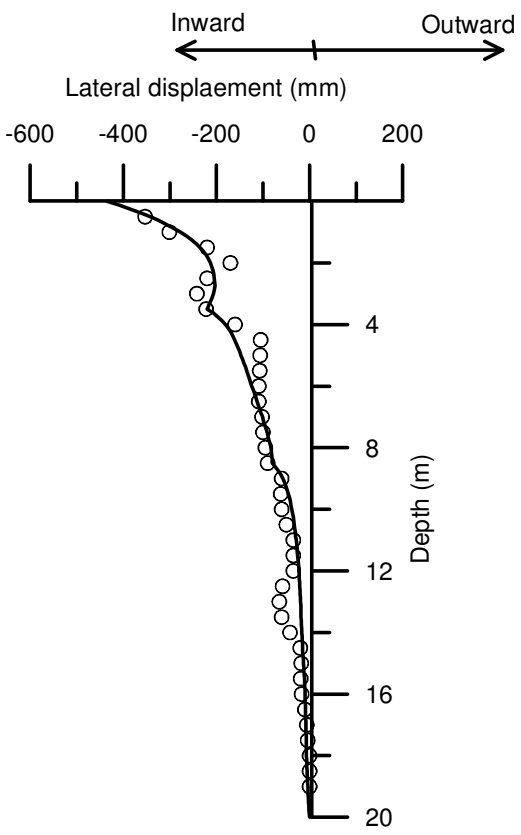

\section{FIG. 10 Lateral displacement after 180days at the embankment toe (adopted from Rujikiatkamjorn et al. 2007)}

\section{CONCLUDING REMARKS}

Some applications and new developments of the vacuum preloading method are summarized. The main advantage of vacuum application is that the surcharge height of embankments on very soft clays can be reduced to prevent any undrained failure. The review presented in this paper has shown that the vacuum preloading method is still evolving and can be further improved. While, the membrane-based method of vacuum application has been conventional, membrane-lesstechniques that apply vacuum pressure directly through PVDs are becoming increasingly commercialized. There is still much potential to expend the capacity of the vacuum preloading methods into new applications by combining them with other ground improvement techniques.

\section{REFERENCES}

Bergado, D.T., Balasubramaniam, A.S., Fannin, R.J., and Holtz, R.D. (2002). "Prefabricated vertical drains (PVDs) in soft Bangkok clay: a case study of the new Bangkok International Airport project." Canadian Geotechnical Journal, Vol. 39, No. 2, 304-315.

Chen, H. and Bao, X.C. (1983). "Analysis of soil consolidation stress under the action of negative pressure." Proc. $8^{\text {th }}$ European Conf. on Soil Mech. and Found. Eng., Helsinki, Vol. 2, 591-596.

Chu, J., Yan, S.W., and Yang, H. (2000). "Soil improvement by vacuum preloading method for an oil storage station". Geotechnique, Vol. 50, No. 6, 625-632.

Chu, J. and Yan, S. W. (2005). "Estimation of degree of consolidation for vacuum 
preloading projects." International Journal of Geomechanics, ASCE, Vol. 5, No, 2, 158-165.

Chu, J. Yan, S.W. and Zheng, Y.R. (2006). "Three soil improvement methods and their applications to road construction." Ground Improvement, Vol. 10, No. 3, 103112.

Holtz, R.D. (1975). "Preloading by vacuum: current prospects." Transportation Research Record, No. 548, 26-79.

Indraratna, B., Bamunawita, C. \& Khabbaz, H (2004). "Numerical Modelling of Vacuum Preloading \& Field Applications." Canadian Geotechnical Journal, Vol. 41, 1098-1110.

Indraratna, B., Rujikiatkamjiorn, C. and Sathananthan, I. (2005). "Analytical And Numerical Solutions for a Single Vertical Drain including the Effects of Vacuum Preloading." Canadian Geotechnical Journal, Vol. 42, NO. 4, 994-1014.

Indraratna, B., Rujikiatkamjorn, C., Balasubramaniam, A.S. and Wijeyakulasuriya (2005). "Prediction and observations of soft clay foundations stabilized with geosynthetic drains and vacuum surcharge." Ch. 7, Ground Improvement Case Histories, Eds. Indraratna, B. and Chu, J., Elsevier, 199-230.

Kjellman, W. (1952). "Consolidation of clayey soils by atmospheric pressure." Proc. of a Conf. on Soil Stabilization, Massachusetts Institute of Technology, Boston, 258-263.

Lindhult, E.C., Tarsavage, J.M. and Foukaris, K.A. (1995). "Remediation in clay using two-phase vacuum extraction." Proc. National Conference on Innovative Technologies for Site Remediation and Hazardous Waste Management, Pittsburgh, Pennsylvania, July 23-26, Ed. by R.D. Vidic and F.G. Pohland, New York: ASCE, $760 \mathrm{pp}$.

Miyazaki, K., Hagiwara, T. and Imamura, S. (2005). "Ground improvement of soft marine clay layer by super well point method.", Proc. Int. Conf. Geot. Eng. for Disaster Mitigation and Rehabilitation, Singapore, 12-13 Dec, Eds. J. Chu, K.K. Phoon and K.Y. Yong, World Scientific.

Tang, M. and Shang, J.Q. (2000). "Vacuum preloading consolidation of Yaoqiang Airport runway." Geotechnique, Vol. 50, No. 6, 613-623.

Seah, T.H. (2006). "Design and construction of ground improvement works at Suvarnabhumi Airport. “ Geot. Eng, J. of Southeast Asian Geot. Society, Vol. 37, 171-188.

Rujikiatkamjorn C., Indraratna, B. and Chu, J. (2007). "Numerical modelling of soft soil stabilized by vertical drains, combining surcharge and vacuum preloading for a storage yard. " Canadian Geotechnical Journal, Vol. 44, 326-342.

Xu, S.L., Lu, X.M., Liu, C.M. and Liu, Y.Y. (2003). "Field trials of the vacuum compaction method for soil improvement." Proc. $9^{\text {th }}$ National Geot. Conf., Beijing, China, Vol. 2, 736-739.

Yan, S.W. and Chu, J. (2005). "Soil improvement for a storage year using the combined vacuum and fill preloading method." Canadian Geotechnical Journal, Vol. 42, No. 4, 2094-1104.

Yan, H.S. and Cao, D.Z. (2005). "Application of low-level vacuum preloading technique in offshore projects." Ocean and River Hydraulics, No. 3, 41-43. 